Editorial

\title{
Spaces, Places, and Geographies of Public Spheres: Exploring Dimensions of the Spatial Turn
}

\author{
Annie Waldherr ${ }^{1, *}$, Ulrike Klinger ${ }^{2}$ and Barbara Pfetsch ${ }^{3}$ \\ ${ }^{1}$ Department of Communication, University of Vienna, Austria; E-Mail: annie.waldherr@univie.ac.at \\ 2 European New School of Digital Studies, European University Viadrina, Germany; E-Mail: klinger@europa-uni.de \\ ${ }^{3}$ Department of Political and Social Sciences, Freie Universität Berlin, Germany; E-Mail: barbara.pfetsch@fu-berlin.de \\ * Corresponding author
}

Submitted: 9 July 2021 | Published: 23 July 2021

\begin{abstract}
For decades, scholars have been calling out a spatial turn in media and communication studies. Yet, in public sphere research, spatial concepts such as space and place have mainly been used metaphorically. In recent years, the abundance of digital trace data offers new opportunities to locate communicative interactions, sparking new interest in the spatial turn in media and communication and opening up new perspectives on spaces and places also within public sphere research. Digital location data enables one to: study the places and spaces in which (semi-)public communication is embedded; uncover geographical inequalities between countries, regions, cities, and peripheries; and highlight the local contexts of public spheres. This thematic issue gathers some of these endeavors in one place, bringing together conceptual, methodological, and empirical contributions that spell out the spatiality of public spheres in detail and combine the analysis of spaces, places, and geographies with long-standing concepts of public sphere research.
\end{abstract}

\section{Keywords}

communication geography; place; public communication; public sphere; space; spatial turn

\section{Issue}

This editorial is part of the issue "Spaces, Places, and Geographies of Public Spheres" edited by Annie Waldherr (University of Vienna, Austria), Ulrike Klinger (European University Viadrina, Germany) and Barbara Pfetsch (Freie Universität Berlin, Germany / Weizenbaum-Institute for the Networked Society, Germany).

(C) 2021 by the authors; licensee Cogitatio (Lisbon, Portugal). This editorial is licensed under a Creative Commons Attribution 4.0 International License (CC BY).

\section{Introduction}

For decades, scholars have been calling out a spatial turn in media and communication studies (e.g., Couldry \& McCarthy, 2004; Jansson \& Falkheimer, 2006), highlighting spaces and places as relevant categories of analysis and acknowledging the spatial embeddedness of media and communication. This focus on the spatiality of communication has been particularly driven by the diffusion of mobile technologies (Sheller, 2017). In the early phase of the emergence of mobile devices, locations, and distances seemed to lose relevance for communication and the "end of geography" was announced (for a discussion see Graham, 1998). Scholars soon reasserted that "geography matters" (Morgan, 2004) and developed the idea that digital and physical spaces co-evolve and recombine, for example, in hybrid spaces (de Souza e Silva, 2006). To date, spatial investigations have been thriving mainly in cultural studies of media and communication devices, as well as more recently in journalism research. In the field of public spheres theories and research, however, the notions of space and place have mainly been used metaphorically and have yet to be spelled out in detail. With this thematic issue, we want to foster the spatial turn in public spheres research and offer a forum for scholars to spell out and explore the different spatial dimensions conceptually and empirically. 


\section{Spaces and Places in Communication Research}

The distinction between place and space is essential for the study of communication geographies (Adams \& Jansson, 2012). Yet, this distinction and the definitions of the terms space and place are contested (for a review, see Usher, 2019). Drawing on the works of Lefèbvre (1991) and Giddens (1984), Löw (2008) puts forward a relational understanding of space. Spaces are "relational orderings of people (living entities) and social goods" (p. 38) which are actively produced through the social processes of spacing (the placing of such entities) and synthesizing (connecting and arranging these placed entities in minds and memories): "In other words, space arises from the activity of experiencing objects as relating to one another" (p. 26). Places then are the specific geographic locations where entities are placed that can be named and which often bear symbolic meanings.

To date, scholars explicitly referring to the spatial turn mainly study how spaces and places give context to communication and mediated action, with a particular focus on mobile technologies (e.g., Humphreys \& Liao, 2011; Waite, 2020). In recent years, there has been increasing interest in the study of how places and spaces are represented, negotiated, and constructed via media and communication. This new interest in geographical analyses of communication is certainly driven by the abundance of digital data facilitating geographical location and annotation of communicators and messages (Hoffmann \& Heft, 2020) and enabling the geographical mapping of social media communication, such as on Twitter (e.g., Bastos et al., 2018; Takhteyev et al., 2012). Journalism scholars have also begun studying the relevance of place and space for news production (Schmitz Weiss, 2015; Usher, 2019). Lindell (2016) points out that communication plays an essential role in the process of constituting and maintaining space. We further argue that the specific interactions of public communication with spaces and places need much more scholarly emphasis and exploration.

\section{Leveraging Spatial Theory and Methodology for Public Sphere Research}

In public sphere research, spatial concepts have been mainly used metaphorically. Habermas, for example, describes the public sphere as a "social space generated in communicative action" (Habermas, 1996, p. 360). Another spatial metaphor is evoked by public arena models (e.g., Neidhardt, 1993), which conceive of public spheres as fora, in which speakers in the arena are competing for the attention of the audience. The theoretical contributions in this issue take these theories of the public sphere as their point of departure, yet criticize their inherent fixation on the nation-state as political space and reference of public deliberation. First, they claim, it is necessary in theory building on public spheres that the spatial dimensions are made explicit and that all aspects of public communication are reflected with respect to their spatiality-be it space, place, or geography. Second, the fundamental digitalization and resulting hybridity of the media infrastructure call for an essential re-conceptualization of public spheres.

The articles published in this thematic issue make central conceptual efforts to this end: They combine public sphere theory with approaches from the sociology of space (Lefèbvre, 1991; Löw, 2008); they emphasize the constructed nature of space through communicative and connected action; and they aim to understand forms of connection and communication across boundariesmapping complex network environments and public discourse in their spatial constellations. Moreover, they maintain that making spatial dimensions visible in communication also allows one to reveal the power relations which underlie the construction of infrastructures.

Daniela Stoltenberg (2021) argues that in contemporary public spheres, and in digital public spheres, in particular, the actors and their networks are disembedded from fixed national territories. She claims that spatiality is an inherent dimension of all conversation about issues, and she develops the concept of "issue spatiality" as a macro-level pattern of public discourses which is enacted on the individual level as a practice of placenaming. Cornelia Brantner et al. (2021) take the sociotechnical argument of increasing complexity and digitalization as a starting point for revising conventional notions of the public sphere. Expanding the "discoursecentered notion of public sphere" (p. 26), they envisage the public sphere as emerging at the interface of discursively structured communication and the assemblage of devices. Communicative spaces are relational, assembled environments in which people may plug in to engage in debate.

Alexa Keinert et al. (2021) carry the infrastructural argument further and emphasize the relational nature of public communication which emerges through human action in the boundedness of space, the fluidity of communication, and the relational character of space. In their view, space in public communication becomes visible through practices of communication within infrastructures of physical territories and at the same time in digital communication networks. Eric Lettkemann and Ingo Schulz-Schaeffer (2021) take the opposite angle and investigate how digital annotations in locative media such as Foursquare influence the perception of places. They distinguish three types of places (transit zones, locales, and locations) according to their perceived accessibility and the elaboration of knowledge one needs to participate.

Zooming out from the study of specific places, the next two contributions take a broader geographical perspective. Marco Bastos (2021) explores geographical metaphors (such as "global village") surrounding social media and the internet, and how they have changed to ideas of tribalism or liberated communities with the turn towards a more pessimistic view on 
digital communication. Morley J. Weston and Adrian Rauchfleisch (2021) empirically connect geography and media coverage by studying the quantity, topics, and sentiments of Chinese newspaper reports about various regions within China and foreign countries. Based on geoparsed text analysis, they show a surprisingly uniform regional coverage, but stark differences in the coverage of other countries.

The last two articles center on local public spheres. Jaana Hujanen et al. (2021) interviewed hyperlocal media producers in Finland, Sweden, and Russia on their roles as information providers, community builders, and civic mediators. They show that not all hyperlocal journalists and media practitioners have the same role conceptions, but that their self-perception depends on their cultural and interactional contexts. Finally, Fischer et al. (2021) develop a system of quantitative indicators to measure and compare the quality of local public spheres across cities and along the dimensions of information, participation, inclusion, and diversity. They argue that local public spheres encompass more than just the local media landscape, but, instead, vary even among similar cities in Germany.

\section{Conclusion}

Taken together, the articles gathered in this thematic issue provide a wealth of insight on spaces, places, and geographies in public spheres. Digital communication, social networks, transnational information flows, discourse dynamics that cross platforms, national borders, and social strata are not placeless or unbound. They touch down, they are anchored and shaped by local, hyperlocal contexts and conditions. Thus, it makes perfect sense to not only understand public sphere(s) as a macro concept, but as diverse, relational, scalable networks that traverse all levels of society and that constitute and are constituted by spaces and places. It is in this light that our thematic issue seeks to promote the spatial turn in public sphere research.

\section{Acknowledgments}

This work is funded by the DFG (Deutsche Forschungsgemeinschaft/German Research Foundation)-project number 290045248-SFB 1265.

\section{Conflict of Interests}

The authors declare no conflict of interest.

\section{References}

Adams, P. C., \& Jansson, A. (2012). Communication geography: A bridge between disciplines. Communication Theory, 22(3), 299-318. https://doi.org/ 10.1111/j.1468-2885.2012.01406.x

Bastos, M. (2021). From global village to identity tribes:
Context collapse and the darkest timeline. Media and Communication, 9(3), 50-58.

Bastos, M., Mercea, D., \& Baronchelli, A. (2018). The geographic embedding of online echo chambers: Evidence from the Brexit campaign. PLOS ONE, 13(11). https://doi.org/10.1371/journal.pone.0206841

Brantner, C., Rodríguez-Amat, J. R., \& Belinskaya, Y. (2021). Structures of the public sphere: Contested spaces as assembled interfaces. Media and Communication, 9(3), 16-27.

Couldry, N., \& McCarthy, A. (Eds.). (2004). MediaSpace: Place, scale and culture in a media age. Routledge.

de Souza e Silva, A. (2006). From cyber to hybrid: Mobile technologies as interfaces of hybrid spaces. Space and Culture, 9(3), 261-278. https://doi.org/10.1177/ 1206331206289022

Fischer, R., Keinert, A., Jarren, O., \& Klinger, U. (2021). What constitutes a local public sphere? Building a monitoring framework for comparative analysis. Media and Communication, 9(3), 85-96.

Giddens, A. (1984). The constitution of society: Outline of the theory of structuration. Polity.

Graham, S. (1998). The end of geography or the explosion of place? Conceptualizing space, place and information technology. Progress in Human Geography, 22(2), 165-185. https://doi.org/10.1191/ 030913298671334137

Habermas, J. (1996). Between facts and norms: Contributions to a discourse theory of law and democracy. Polity.

Hoffmann, M., \& Heft, A. (2020). "Here, there and everywhere": Classifying location information in social media data-Possibilities and limitations. Communication Methods and Measures, 14(3), 184-203. https://doi.org/10.1080/19312458.2019.1708282

Hujanen, J., Dovbysh, O., Jangdal, L., \& Lehtisaari, K. (2021). Towards (hyper)local public sphere: Comparison of civic engagement across the Global North. Media and Communication, 9(3), 74-84.

Humphreys, L., \& Liao, T. (2011). Mobile geotagging: Reexamining our interactions with urban space. Journal of Computer-Mediated Communication, 16(3), 407-423.

Jansson, A., \& Falkheimer, J. (2006). Towards a geography of communication. In J. Falkheimer \& A. Jansson (Eds.), Geographies of communication: The spatial turn in media studies (pp. 7-23). Nordicom.

Keinert, A., Sayman, V., \& Maier, D. (2021). Relational communication spaces: Infrastructures and discursive practices. Media and Communication, 9(3), 28-38.

Lefèbvre, H. (1991). The production of space. Blackwell.

Lettkemann, E., \& Schulz-Schaeffer, I. (2021). Transit zones, locales, and locations: How digital annotations affect communication in public places. Media and Communication, 9(3), 39-49.

Lindell, J. (2016). Communication as spatial production: Expanding the research agenda of communication 
geography. Space and Culture, 19(1), 56-66. https:// doi.org/10.1177/1206331215596480

Löw, M. (2008). The constitution of space: The structuration of spaces through the simultaneity of effect and perception. European Journal of Social Theory, 11(1), 25-49. https://doi.org/10.1177/1368431007085286

Morgan, K. (2004). The exaggerated death of geography: Learning, proximity and territorial innovation systems. Journal of Economic Geography, 4(1), 3-21. https://doi.org/10.1093/jeg/4.1.3

Neidhardt, F. (1993). The public as a communication system. Public Understanding of Science, 2(4), 339-350. https://doi.org/10.1088/0963-6625/2/4/004

Schmitz Weiss, A. (2015). Place-based knowledge in the twenty-first century. Digital Journalism, 3(1), 116-131. https://doi.org/10.1080/21670811.2014. 928107

Sheller, M. (2017). From spatial turn to mobilities turn. Current Sociology, 65(4), 623-639. https://doi.org/ $10.1177 / 0011392117697463$
Stoltenberg, D. (2021). Issue spatiality: A conceptual framework for the role of space in public discourses. Media and Communication, 9(3), 5-15.

Takhteyev, Y., Gruzd, A., \& Wellman, B. (2012). Geography of Twitter networks. Social Networks, 34(1), 73-81. https://doi.org/10.1016/j.socnet.2011.05. 006

Usher, N. (2019). Putting "place" in the center of journalism research: A way forward to understand challenges to trust and knowledge in news. Journalism \& Communication Monographs, 21(2), 84-146. https:// doi.org/10.1177/1522637919848362

Waite, C. (2020). Making place with mobile media: Young people's blurred place-making in regional Australia. Mobile Media \& Communication, 8(1), 124-141. https://doi.org/10.1177/2050157919843963

Weston, M. J., \& Rauchfleisch, A. (2021). Close to Beijing: Geographic biases in People's Daily. Media and Communication, 9(3), 59-73.

\section{About the Authors}

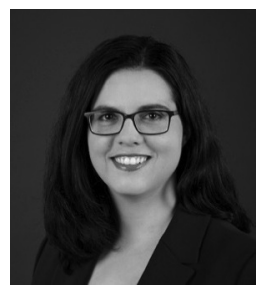

Annie Waldherr (PhD) is Professor of Computational Communication Science in the Department of Communication at the University of Vienna. Previously, she worked as Assistant Professor at the University of Münster and held positions as Research Associate at Freie Universität Berlin and the University of Hohenheim. She studies the changing structures and dynamics in today's digitized public spheres, combining computational and conventional empirical methods.

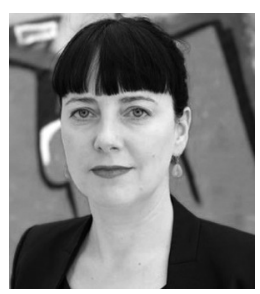

Ulrike Klinger (PhD) is Professor for Digital Democracy at the European University Viadrina and Associated Researcher at the Weizenbaum Institute for the Networked Society in Berlin. She was Professor for Digital Communication at Freie Universität Berlin and Head of the research group on "News, Campaigns and the Rationality of Public Discourse" at the Weizenbaum Institute. Her research focuses on political and digital communication, the transformation of digital public spheres, the role of digital media in election campaigns, and the impact of technologies on public communication.

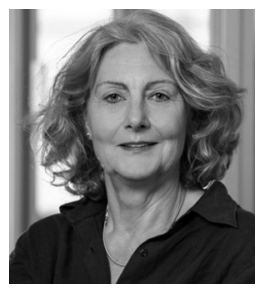

Barbara Pfetsch (PhD) is Professor of Communication Theory and Media Effects Research in the Institute for Media and Communication Studies at Freie Universität Berlin. She is also Principal Investigator at the Weizenbaum Institute for the Networked Society in Berlin. She earned her PhD from the University of Mannheim and held positions at the Berlin Social Science Center (WZB) and the University of Hohenheim. Her research and publications focus on comparative political communication, online communication and digital issue networks, and transnational and European public spheres. 